\title{
Subendocardial to subepicardial absolute myocardial blood flow at rest and hyperaemia determined by first pass-cmr and fermi deconvolution modelling
}

\author{
Abdulghani M Larghat*1, Aleksandra Radjenovic ${ }^{1}$, Neil Maredia1, \\ John Biglands ${ }^{1}$, John P Greenwood ${ }^{1}$, Jerosch Herold ${ }^{2}$ and Sven Plein ${ }^{1}$
}

Address: ${ }^{1}$ University of Leeds, Leeds, UK and ${ }^{2}$ Brigham and Women's Hospital, Boston, MA, USA

* Corresponding author

from 13th Annual SCMR Scientific Sessions

Phoenix, AZ, USA. 2I-24 January 2010

Published: 21 January 2010

Journal of Cardiovascular Magnetic Resonance 20 I0, I 2(Suppl I):P223 doi:I0.I I86/I532-429X-I2-SI-P223

This abstract is available from: http://jcmr-online.com/content/I2/SI/P223

(C) 2010 Larghat et al; licensee BioMed Central Ltd.

\section{Introduction}

Currently PET, SPECT and echocardiography are used to estimate myocardial blood flow, however with limited ability to evaluate transmural flow difference [1]. With its higher spatial resolution CMR is particularly suited to assess transmural variation in myocardial blood flow [2]. Only one previous CMR study reported differences in subendocardial and subepicardial (3).

\section{Purpose}

To compare subendocardial and subepicardial estimates of absolute myocardial blood flow (AMBF) based on first pass perfusion CMR at rest and hyperaemic stress.

\section{Methods}

10 volunteers ( 7 male, mean age 38 years) were studied on a $1.5 \mathrm{~T}$ Philips Intera system during adenosine induced hyperaemia $(140 \mathrm{mcg} / \mathrm{kg} / \mathrm{min}$ for 3 minutes, $0.05 \mathrm{mmol} /$ kg Gd-DTPA) and at rest. A pulse sequence optimised for acquisition of a single midventricular slice at systole was used (saturation recovery segmented gradient echo, $2 \times$ SENSE TR/TE/flip 2.7 ms/1.0/15, typical FOV $380 \times 380$ $\mathrm{mm}$, matrix $160 \times 160$, slice thickness $10 \mathrm{~mm}$, preparation pulse delay $150 \mathrm{~ms}$, shot duration $130 \mathrm{~ms}$ ). Endo and epicardial contours were drawn and the slice segmented into 6 equidistant sectors. These were further subdivided into epicardial, mid-myocardial and endocardial thirds. Based on LV and blood pool time intensity curves, an inhouse mathematical Fermi Function deconvolution algo- rithm was implemented to estimate absolute myocardial blood flow [2].

\section{Results}

All results are in $\mathrm{ml} / \mathrm{g} / \mathrm{min}$. The 6 myocardial segments yielded mostly comparable values (Fig 1), except for hyperaemic AMBF (Fig 1B). The mean AMBF of all 6 segments at rest was lower in the subendocardium than the subepicardium $(1.70 \pm 0.13$ vs. $2.00 \pm 0.16 \mathrm{p}=0.005)$, Fig $1 \mathrm{~A}$. The mean AMBF during hyperaemia was $4.41 \pm 0.33$ (subepicardium) and $3.93 \pm 0.13$ (subendocardium), $\mathrm{P}<$ 0.001, Fig 1B. The mean AMBF Reserve Index between stress and rest was $2.83 \pm 0.18$ for the subepicardium and $2.12 \pm 0.12$ for the subendocardium, $\mathrm{P}<0.00001$, Fig1C. The ratio of endocardial to epicardial AMBF was $1.22(+/-$ $0.07)$ at rest and $0.91(+/-0.09)$ during hyperaemia, $\mathrm{P}<$ 0.00001 , Fig 1D.

\section{Conclusion}

1. Differences in endocardial and epicardial AMBF gradients can be detected with CMR in vivo.

2. In all myocardial segments the subendocardial layer has a higher resting perfusion than the subepicardial layer.

3. The subepicardium has a higher hyperaemic AMBF and perfusion reserve than the subendocardium. Unlike previ- 

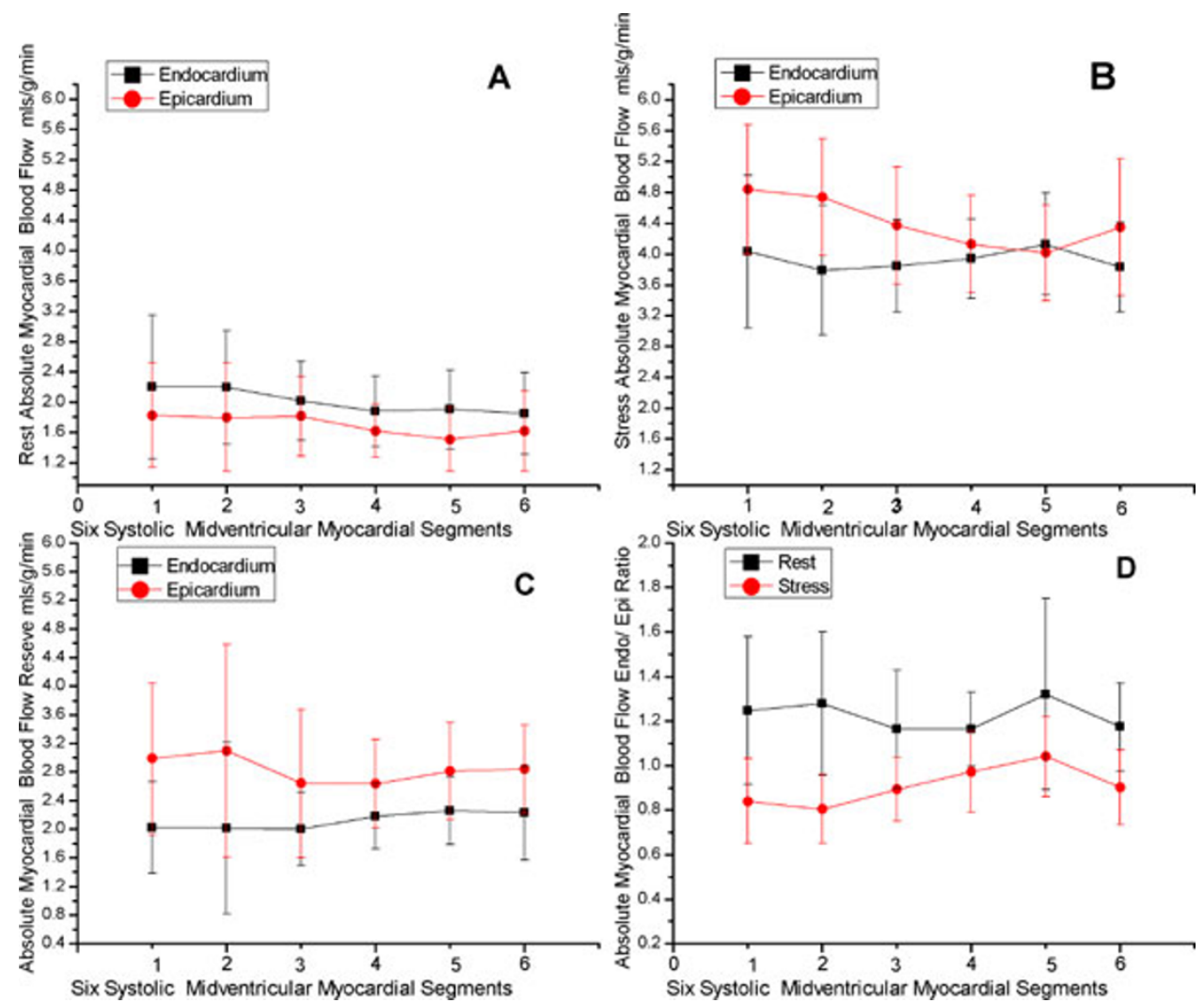

Figure I

ous studies, we acquired all AMBF data in systole, which may explain this novel finding.

\section{References}

I. Laxson DD, et al:: Circulation 1992, 85:3 | 3-322.

2. Jerosch-Herold M, et al.: Med Phys 1998, 25:73-84. 